\title{
Особенности газофазной эпитаксии GaAs на непланарных подложках
}

\author{
(С) Ю.Н. Дроздов, С.А. Краев, А.И. Охапкин, В.М. Данильцев, Е.В. Скороходов \\ Институт фризики микроструктур Российской академии наук, \\ 603950 Нижний Новгород, Россия \\ E-mail: drozdyu@ipmras.ru
}

Поступила в Редакцию 15 апреля 2020 г.

В окончательной редакции 21 апреля 2020 г.

Принята к публикации 21 апреля 2020 г.

\begin{abstract}
Исследованы особенности формы поверхности эпитаксиальных слоев GaAs, выращенных на канавках шириной в несколько микрометров с вертикальными стенками и аспектным соотношением, близким к единице. Канавки формировались на поверхности пластины GaAs в установке плазмохимического травления, заращивались методом металлоорганической газофазной эпитаксии при пониженном давлении в реакторе.
\end{abstract}

Ключевые слова: плазмохимическое травление GaAs, узкие канавки, эпитаксия GaAs в канавках.

DOI: $10.21883 /$ FTP.2020.09.49839.33

\section{1. Введение}

Длинные канавки на поверхности GaAs глубиной и шириной в несколько микрометров могут быть основой для создания ряда полупроводниковых приборов, если канавка заполнена эпитаксиальным слоем GaAs одного типа легирования, а проделана она в слое GaAs другого типа. Запатентованы, в частности, конструкции горизонтального и вертикального транзисторов, которые используют два $p-n$-перехода, образующиеся на стенках узкой канавки. Технология GaAs в настоящее время хорошо отработана, но обычно это планарный послойный рост. Заращивание узких канавок происходит намного сложнее, что сдерживает развитие промышленных технологий. Возникает много особенностей, но в настоящем сообщении основное внимание уделено морфологии ростового фронта внутри канавки и по ее краям.

Из литературных данных известно, что узкие канавки на поверхности $\mathrm{GaAs}(001)$ могут быть получены методом химического [1] или плазмохимического травления [2]. Для последующего эпитаксиального наращивания химическое травление предпочтительнее, поскольку создает минимальный нарушенный слой. Однако наклон стенок при химическом травлении существенно зависит от направления канавок. Бо́льшая устойчивость поверхностей (111)Ga в сравнении с (111)As проявляется в том, что на поверхности $\mathrm{GaAs}(001)$ канавки, нанесенные вдоль направления [110] сужались по глубине, а вдоль направления [110] — расширялись [1], как это показано на рис. 1.

Наши предварительные эксперименты по жидкофазному травлению канавок подтвердили картину, представленную на рис. 1. Канавки по диагонали между показанными на рис. 1 направлениями могут иметь близкие к вертикальным стенки, но жидкофазное травление приводит к недопустимому расширению вбок за счет подтрава маски. Подтрав под маску не позволяет получить глубокие и в то же время узкие канавки, необходимые для транзисторов. Более подходящим оказался плазмохимический метод травления.

В настоящей работе исследованы особенности формы поверхности эпитаксиальных слоев GaAs, выращенных на канавках шириной в несколько микрометров с вертикальными стенками и аспектным соотношением, близким к единице. Основное внимание уделено начальной стадии заращивания канавок, когда формируются наклонные стенки эпитаксиальных слоев GaAs внутри и в окрестности канавки.

\section{2. Эксперимент}

Канавки на поверхности GaAs формировали методом плазмохимического травления на установке Oxford Plasmalab 80 в индуктивно-связанной плазме аналогично данным работы [2]. Напряжение смещения составило $\sim 180$ В. Использовали $\mathrm{Cl}_{2}+\mathrm{BCl}_{3}$ плазму (общий поток $25 \mathrm{~cm}^{3} / \mathrm{Mин,} \mathrm{давление} \mathrm{-} 12$ мТорр). Индуктивносвязанный разряд в качестве источника плазмы позволил

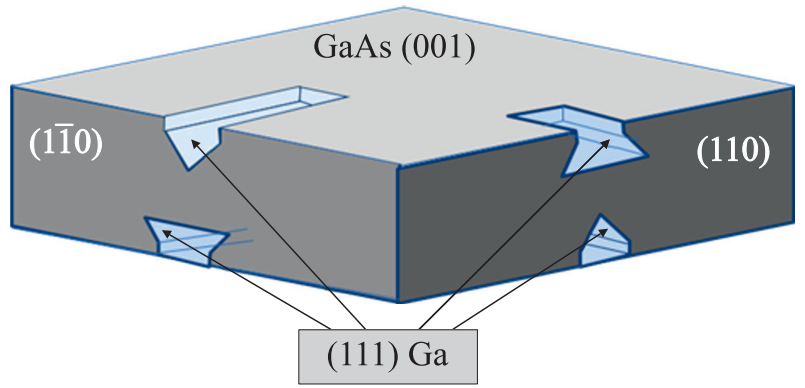

Рис. 1. Схема строения канавок, вытравленных на поверхности $\operatorname{GaAs}(001)$ в двух направлениях методом жидкостного химического травления по данным работы [1]. 
проводить травление с высокой скоростью без значительного ионного воздействия на материал подложки. При этом применялся импульсный режим, состоящий из чередования циклов травления и бездействия во избежание перегрева и деградации фоторезистивной маски. Канавки имели глубину и ширину в несколько микрометров и длину 100 мкм. Заращивание эпитаксиальным слоем GaAs проводили в установке металлоорганической газофазной эпитаксии EPIQUIP VP-502RP при пониженном давлении в реакторе (100 мБар) в зоне роста, что необходимо для доставки газов внутрь узкой канавки при эпитаксиальном росте. Газом-носителем являлся водород. В качестве реагентов использовали триметилгаллий $-\mathrm{Ga}\left(\mathrm{CH}_{3}\right)_{3}$ и арсин $-\mathrm{AsH}_{3}$. Температура подложки была $600^{\circ} \mathrm{C}$.

Поверхность анализировали методом сканирующей электронной микроскопии (SEM) с использованием Supra 50VP и Neon-40, в том числе с использованием сколов по плоскостям спайности пластин GaAs.

\section{3. Результаты и обсуждение}

Использованный режим плазмохимического травления позволил сформировать вертикальные стенки канавки независимо от направления на подложке (см. рис. 2).

На рис. 3 показан вид поперечного сечения канавки шириной $\sim 3$ мкм после заращивания тонким слоем GaAs.

Видно, что внутри канавки (области I) и снаружи (области II) формируются наклонные стенки, угол наклона стенок $\sim 35^{\circ}$. Канавка была ориентирована вдоль направления [110] подложки.

Отклонение этих стенок от вертикали позволяет идентифицировать их как плоскости типа (111), для которых рассчитанный угол составляет $35.3^{\circ}$. Огранка

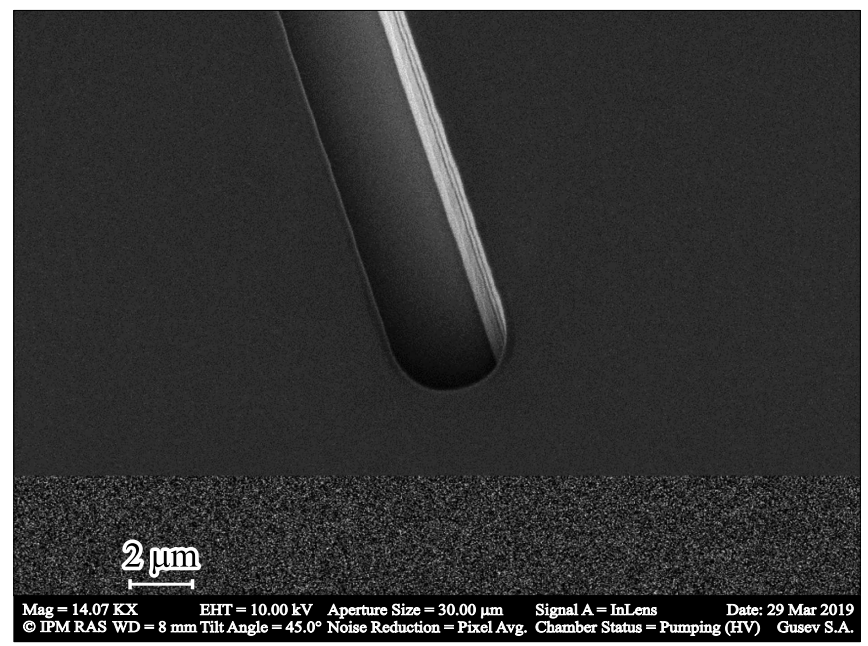

Рис. 2. Вид канавки шириной $\sim 3$ мкм вблизи торца. Направление канавки не совпадало с основными кристаллографическими направлениями на поверхности $\mathrm{GaAs}(001)$.

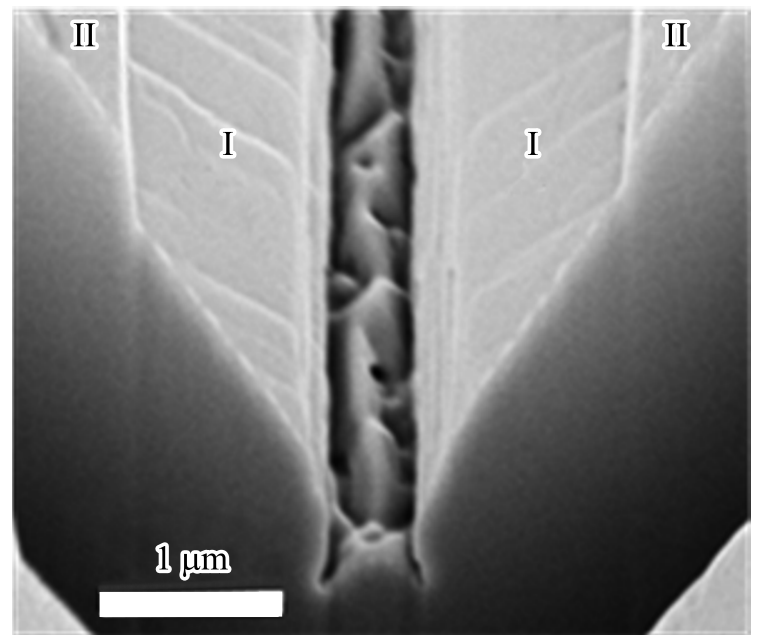

Рис. 3. Вид поперечного сечения канавки на начальном этапе заращивания. Наклонные стенки эпитаксиального GaAs: I внутри канавки, II - вне канавки.
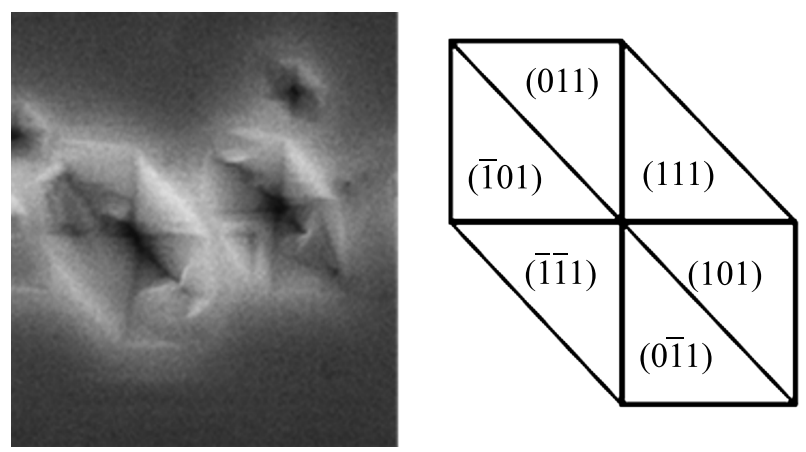

Рис. 4. Огранка ямок в эпислое на дне канавки, $2 \times 2$ мкм, и идеализированная форма ямки. Плоскости (111) и (111) это плоскости типа (111)Ga при выборе начала координат на атоме Ga.

(111) возникает из-за того, что это самая медленнорастущая грань, являющаяся плотноупакованной в кристалле GaAs. В канавках, ориентированных вдоль ортогонального к первому направлению, угол наклона стенок был таким же, в отличие от формы стенок при жидкостном травлении (рис. 1), хотя процессы послойного роста и послойного травления в первом приближении взаимно обратимы. В канавках, ориентированных под углом $45^{\circ}$ к боковым срезам, наклон стенок был близок к $45^{\circ}$, что позволяет идентифицировать их как плоскости типа (101).

Более полно и наглядно формы роста видны на ограненных ямках, образовавшихся на локальных загрязнениях поверхности при эпитаксиальном заращивании с недостаточной очисткой поверхности после травления канавок. В общем случае форма ямок зависит от условий роста и легирования слоев. Пример ямок и их идеализированная форма показаны на рис. 4. 
Хорошо видны грани тетраэдра и ромбододекаэдра, которые идентифицируются по направлению линий пересечения между собой и с поверхностью (001). Поверхности (111)As выражены гораздо слабее, чем плоскости (111) Ga, и даже слабее, чем (101). Эта закономерность согласуется с данными по анизотропному жидкостному травлению канавок [1]. В отличие от этого, в длинных канавках, ориентированных вдоль направления [110], угол наклона был $\sim 35^{\circ}$, что позволяет идентифицировать стенки как (111)As. По-видимому, эти поверхности становятся устойчивыми из-за наличия углового излома на дне ямки на начальном этапе эпитаксиального роста GaAs в канавке.

Такая закономерность имеет важное значение для объяснения формы боковых стенок при росте эпитаксиального слоя при наличии канавки, проделанной на поверхности $\mathrm{GaAs}(001)$ вдоль различных направлений относительно бокового среза. Если канавка направлена вдоль направления [110] или [110], то плоскостями боковой стенки становятся грани типа (111). Если канавка идет под углом $\pm 45^{\circ}$ к линии бокового среза, то боковая стенка внутри и вне канавки имеет грань ромбододекаэдра, наклоненную на $45^{\circ}$ к поверхности подложки. Это расширяет на $43 \%$ область, занимаемую краями одной канавки на поверхности, и должно учитываться при их плотном размещении на подложке. Другие особенности непланарной эпитаксии, затрудняющие ее использование, - это различие в коэффициентах вхождения легирующей примеси для различных граней кристалла, а также полисекторный рост, при котором на стыке плоских поверхностей роста могут формироваться дефекты. Тем не менее при тщательной очистке поверхности после плазмохимического травления удается зарастить канавку эпитаксиальным слоем GaAs, и поверхность достаточно хорошо планаризуется.

Следует отметить, что выражение „канавки, идущие вдоль направления [110], сужаются по глубине, а вдоль направления [110] - расширяются“", вступает в противоречие с эквивалентностью этих двух направлений в кристаллической структуре GaAs. В структуре имеются поворотные оси 2-го порядка (вдоль координатных осей). На рис. 5 показана такая ось (в составе четверной инверсионной оси $\overline{4}$ ) вдоль оси $x$.

Она связывает и делает симметрично эквивалентными (структурно идентичными) противоположные поверхно-

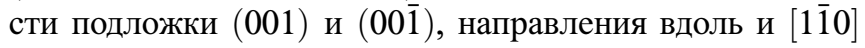
и [110], а также плоскости первичного и вторичного

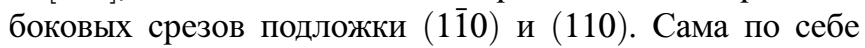
поверхность GaAs (001) анизотропна, что связано с положением наклонных плоскостей (111)Ga и (111)As. Направления к этим плоскостям различаются, например, по форме ямок травления - типа ямок на рис. 3. Однако абсолютные значения индексов боковых плоскостей срезов можно указать лишь после того, как поверхность самой подложки обозначена (001), а не $(00 \overline{1})$. После переворота подложки лицом вниз тип боковых плоскостей меняется, что наглядно видно на

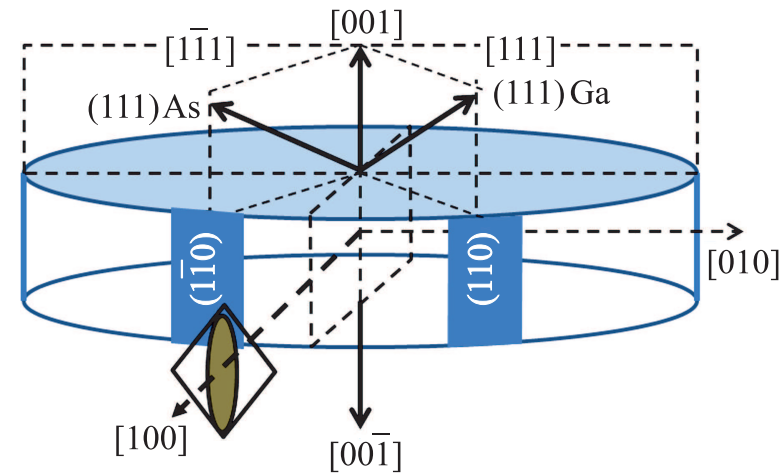

Рис. 5. Вид подложки $\mathrm{GaAs}(001)$ с указанием основных кристаллографических направлений. Показана четверная инверсионная ось вдоль оси х, плоскости боковых срезов подложки (110) и (110), а также нормали к двум плоскостям типа (111)Ga и (111)As.

рис. 1 - на одну и ту же боковую поверхность сверху выходит сужающаяся канавка, а снизу - расширяющаяся. Однозначным в этих условиях было бы описание двух неэквивалентных направлений на поверхности пластины GaAs (001) следующим образом: „направление отклонения от нормали к ближайшей плоскости типа (111) Ga или (111)As“, которое в настоящее время и используется для корректного описания отклонения срезов подложки GaAs от (001) [3]. Это позволяет „отстроиться“ даже от неоднозначности, связанной с выбором начала координат в структуре сфалеритного типа либо на атоме $\mathrm{Ga}$ - стандартный выбор, где поверхность кристалла с индексами $(+1+1+1)-$ это плоскость типа $(111) \mathrm{Ga}$, либо на атоме $\mathrm{As}$, и тогда $(+1+1+1)$ - это плоскость (111)As.

\section{4. Заключение}

Таким образом, анизотропия свойств кристалла играет существенную роль и при травлении, и при росте эпитаксиальных слоев GaAs. Ee приходится учитывать в непланарных технологиях. Например, смена ориентации длинных канавок с параллельного базовому срезу направления на 45-градусное расширяет на 43\% область, занимаемую краями одной канавки на поверхности, и должно учитываться при их плотном размещении на подложке.

\section{Финансирование работы}

Работа выполнена в рамках государственного задания № 0035-2019-0024-С-01 для ИФМ РАН. Использовано оборудование центра коллективного пользования „Физика и технология микро- и наноструктур“.

\section{Конфликт интересов}

Авторы заявляют, что у них нет конфликта интересов. 


\section{Список литературы}

[1] L. Comerford, P. Zory. Appl. Phys. Lett., 25, 208 (1974).

[2] W. HaiLing, G. Xia, S. GuangDi. Sci. China Ser. E, 50 (6), 749 (2007).

[3] http://www.galaxywafer.com/galaxy/products/categories-of-offorientation/

Редактор А.Н. Смирнов

\section{Features of gas-phase epitaxy of GaAs on non-planar substrates}

Yu.N. Drozdov, S.A. Kraev, A.I. Ohapkin, V.M. Daniltsev, E.V. Skorokhodov

Institute for Physics of Microstructures,

Russian Academy of Sciences,

603950 Nizhny Novgorod, Russia

Abstract The features of the surface shape of GaAs epitaxial layers grown on grooves several micrometers wide with vertical walls and aspect ratio close to unity were studied. Grooves were formed on the surface of a GaAs wafer in a plasma-chemical etching unit, and were overgrown by organometallic gas-phase epitaxy under reduced pressure in a reactor. 